\title{
A New Validated Method for the Estimation of Amisulpride in Bulk and Pharmaceutical Dosage Form by Using Reverse Phase Liquid Chromatographic Method
}

\author{
Potturi Rama Devi and Kantipudi Rambabu \\ Department of Chemistry, RVR \& JC College of Engineering, Chowdavaram, \\ Guntur, Andhra Pradesh, India Corresponding author email: ramadeviresearchanu@gmail.com
}

\section{ABSTRACT}

New validated method for the estimation of Amisulpride In Bulk and Pharmaceutical Dosage Form By Using Reverse Phase Liquid Chromatographic Method Chromatographic separation was achieved on a inertsil ODS column (150x4.6mm, $3.5 \mu$ ) using isocratic elution with a mobile phase containing buffer and acetonitrile within the ratio of 30:70 as mobile phase with a flow of $1 \mathrm{ml} / \mathrm{min}$ at ambient temperature and UV detection was carried at $257 \mathrm{~nm}$. Analysis was achieved within $5 \mathrm{~min}$ over an honest linearity within the concentration range from 1-15 $\mu \mathrm{g} / \mathrm{ml}$ of Amisulpride. By injecting the standard six times, system suitability parameters were studied and the outcomes were well under the acceptance criteria. Precision and recovery study results were found to be within the suitable limit. By using the above technique assay of marketed formulation was performed and found to be within the limit. Degradation studies were carried out on Amisulpride, with a purity threshold greater than purity angle in all conditions and within the acceptable range. The above mentioned technique was validated according to ICH guidelines.

KEY WORDS: HPLC, AMISULPRIDE, DEVELOPMENT, VALIDATION, DEGRADATION STUDIES.

\section{INTRODUCTION}

Amisulpride is an antiemetic and antipsychotic medication used at lower doses intravenously to prevent and treat postoperative nausea and vomiting; and at higher doses orally and intramuscularly to treat schizophrenia and acute psychotic episodes. It is sold under the brand names Barhemsys (as an antiemetic) and Solian, Socian, Deniban and others (as an antipsychotic). It is also used to treat dysthymia. It is usually classed with the atypical antipsychotics. Chemically it is a benzamide and like other benzamide antipsychotics, such as sulpiride, it is associated with a high risk of elevating blood levels of the lactation hormone, prolactin (thereby potentially causing the absence of the menstrual cycle, breast enlargement, even in males, breast milk secretion not related to breastfeeding, impaired fertility, impotence, breast pain, etc.), and a low risk, relative to the typical antipsychotics,

Biosc Biotech Res Comm P-ISSN: 0974-6455 E-ISSN: 2321-4007
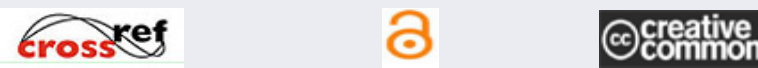

Identifiers and Pagination

Article Information

Year: 2021 Vol: 14 No (9) Special Issue

Pages: 189-193

Received: $18^{\text {th }}$ May 2021

This is an open access article under Creative

Commons License Attribn 4.0 Intl (CC-BY).

DOI: $h t t p: / / d x . d o i . o r g / 10.21786 / b b r c / 14.9 .36$ of causing movement disorders. Amisulpride is believed to work by blocking, or antagonizing, the dopamine D2 receptor, reducing its signalling. The effectiveness of amisulpride in treating dysthymia and the negative symptoms of schizophrenia is believed to stem from its blockade of the presynaptic dopamine D2 receptors. These presynaptic receptors regulate the release of dopamine into the synapse, so by blocking them amisulpride increases dopamine concentrations in the synapse. This increased dopamine concentration is theorized to act on dopamine D1 receptors to relieve depressive symptoms (in dysthymia) and the negative symptoms of schizophrenia (Agarwal et al., 2016).

Figure 1: Chemical structure of Amisulpride

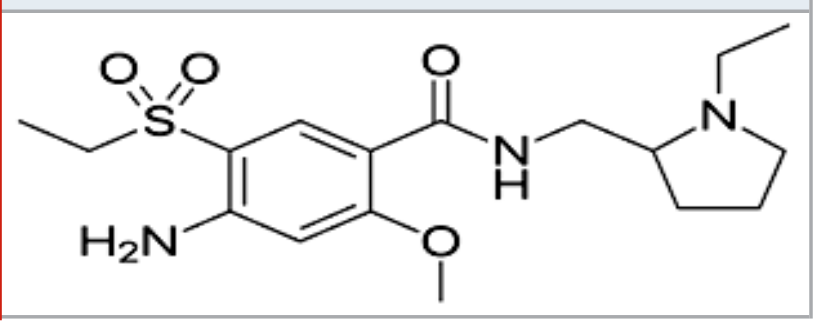




\section{MATERIAL AND METHODS}

2.1 Materials: Acetonitrile and Tri fluoro acetic acid, water (HPLC grade) were purchased from Merck (India) Ltd, Worli, Mumbai, India. API of Amisulpride as reference standard was procured from Laurus Labs Pvt. Ltd., Hyderabad (Capuco \&t Akers 2009).

2.2 Tools: An HPLC system (Waters alliance e2695 model) consisting of quaternary pump, PDA detector-2998 was used. Data processing was performed with Empower 2.0 software (Carmichael et al., 2021).

2.3 Chromatographic conditions: Chromatographic separation was carried out in isocratic mode at room temperature using inestsil ODS column $(150 \times 4.6 \mathrm{~mm}$, $3.5 \mu$ ). A mixture of acetonitrile and $0.1 \%$ tri fluoro acid (TFA) in 70:30 v/v at a flow of $1 \mathrm{ml} / \mathrm{min}$ was used as mobile phase. The injection volume was $10 \mu \mathrm{l}$ and the run time was 5.0 min (Frederick et al., 2014).

2.4 Preparation of buffer: $1 \mathrm{ml}$ of tri fluoro acetic acid is dissolved in 1 lt of HPLC grade water and filtered through $0.45 \mu$ filter paper (Gerlo et al., 2006).

2.5 Diluent: Acetonitrile was used as diluent.

2.6 Preparation of standard and quality control samples: Accurately weigh and transfer $10 \mathrm{mg}$ of Amisulpride in $100 \mathrm{ml}$ volumetric flask and add app. $70 \mathrm{ml}$ of diluent, sonicate to dissolve it for $30 \mathrm{~min}$. and made up to the mark with diluent. Furthur dilute $5 \mathrm{ml}$ of the above solution to $50 \mathrm{ml}$ with diluents.

2.7 Preparation of sample solution: Accurately weigh and transfer weight equivalent to $10 \mathrm{mg}$ of Amisulpride sample in $100 \mathrm{ml}$ of volumetric flask and add $70 \mathrm{ml}$ of diluent. Sonicate to dissolve and dilute up to the mark with diluent. Take $5 \mathrm{ml}$ of the above solution and diluted to $50 \mathrm{ml}$ and filtered through $0.45 \mu$ nylon syringe filter (Giardina et al., 2006).

\subsection{Method Validation}

2.8.1 System suitability: System suitability parameters were measured to verify the system performance. The parameters including USP plate count, USP tailing and \% of RSD are calculated and found to be within the limit.

2.8.2 Specificity: Specificity is the ability to assess unequivocally the analyte in the presence of other components, which may be expected to be present in the sample and standard solution. It was checked by examining the chromatograms of blank samples and samples spiked with Amisulpride.

2.8.3 Accuracy:Accuracy is the closeness of the test results obtained by the method to the true value. It was assessed by the recovery studies at three different concentration levels. In each level a minimum of three injections were given and amount of the drug present, percentage recovery and related standard deviation were calculated.

2.8.4 Precision: Precision of the analytical method is the degree of agreement among individual test results. It was studied by analysis of multiple sampling of homogeneous sample. The precision of the present method was assessed in terms of repeatability, intraday and inter-day variations. It was checked by analyzing the samples at different time intervals of the same day as well as on different days.

2.8.5 Linearity: Linearity of an analytical method is its ability to obtain results directly proportional to the concentration of the analyte in the sample within a definite range. The six series of standard solutions were selected for assessing linearity range. The calibration curve was plotted using peak area versus concentration of the standard solution and the regression equations were calculated. The least squares method was used to calculate the slope, intercept and correlation coefficient.

2.8.6 Stress degradation: Stress degradation should be no interference between the peaks obtained for the chromatogram of forced degradation preparations. Stress degradation studies were performed as per ICH guidelines Q1 (A) R2. The degradation peaks should be well separated from each other and the resolution between the peaks should be at least 1.0 and the peak purity of the principle peaks shall pass. Forced degradation studies were performed by different types of stress conditions to obtain the degradation of about $20 \%$.

2.8.7 Robustness: Robustness of an analytical procedure is a measure of its ability to remain unaffected by small but deliberate variations in method parameters and provides an indication of its reliability during normal usage. Robustness study was performed by injecting standard solution into the HPLC system and altered chromatographic conditions such as flow rate $( \pm 0.2 \mathrm{ml} /$ min), organic content in the mobile phase $( \pm 10 \%)$. The separation factor, retention time and peak asymmetry were calculated by determining the effect of the modified parameters (Goikolea et al., 2013).

\section{RESULTS AND DISCUSSION}

The current study was designed to develop a simple, precise and rapid analytical RP-HPLC method, which can be used for the analysis of assay method for the estimation of Amisulpride in bulk and pharmaceutical dosage form. The chromatographic conditions were optimized in order to provide a good performance of the assay. To optimize mobile phase, various combinations were tried for Amisulpride. The final working mobile phase is $0.1 \%$ tri fluoro acetic acid and acetonitrile in the composition of 30:70 v/v. Detection was carried out in several wavelengths in order to obtain enough sensitivity for the two APIs in smaller proportion (Amisulpride). At last the wave length $257 \mathrm{~nm}$ was selected at which the drug showed good absorbance. The flow rate was 1.0 $\mathrm{ml} / \mathrm{min}$. The retention time for Amisulpride was 2.423 
min respectively. The proposed method is validated in accordance with the ICH guidelines with all of the results within the limits. The detection was carried out with a total runtime of 5.0 min. Optimized chromatographic conditions were shown in table 1.

Table 1. Optimized chromatographic conditions

\begin{tabular}{|l|c|}
\hline \multirow{2}{*}{ Parameter } & Condition \\
\hline Stationary phase & Inertsil ODS (150x4.6 mm, 3.5 $\mu$ ) \\
\hline Mobile phase & $0.1 \%$ TFA: Acetonitrile (30:70) \\
\hline Injection volume & $10 \mu \mathrm{l}$ \\
\hline Flow rate & $1.0 \mathrm{ml} / \mathrm{min}$ \\
\hline Column temperature & $25^{\circ} \mathrm{C}$ \\
\hline Wave length & $257 \mathrm{~nm}$ \\
\hline Run time & $5.0 \mathrm{~min}$ \\
\hline Retention time of \\
Amisulpride
\end{tabular}

*TFA : Tri fluoro acetic acid nm: Nanometer

System suitability: The system suitability was performed by injecting standard solution containing $10 \mu \mathrm{g} / \mathrm{ml}$ of Amisulpride in six replicates. The results indicate that the system suitability parameter is within the limit. The standard chromatogram was shown in figure 2 .

Figure 2: Chromatogram of system suitability

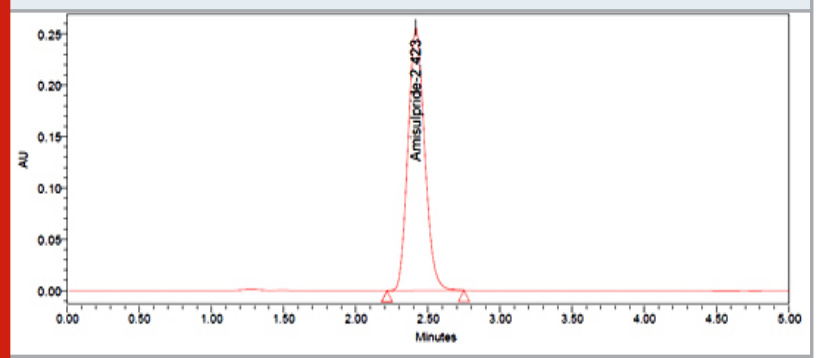

Figure 3: Chromatogram of blank

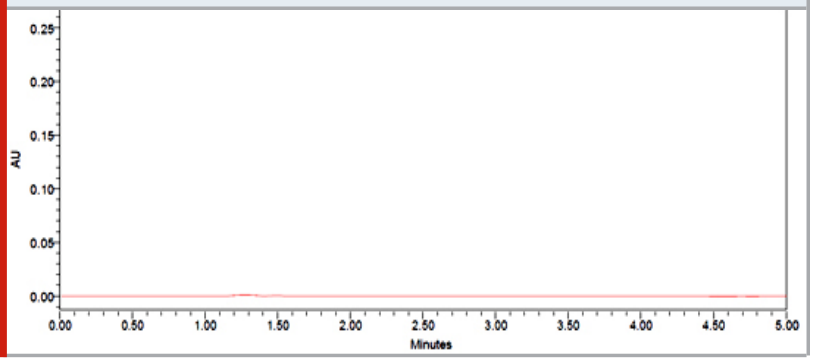

Specificity: There was no interference from blank at the retention time of Amisulpride. Figure 3 represents the blank chromatogram (Honarmand et al., 2016).

Linearity: Linearity was determined by plotting a calibration curve of peak area against their respective concentration. From this calibration curve it was found that the curve was linear in the range of $1-15 \mu \mathrm{g} / \mathrm{ml}$ of Amisulpride. The regression equation for calibration curve of Amisulpride was $\mathrm{Y}=371398.70 \mathrm{x}+16090.61$ (R2-0.9998), the results were shown in table 2 and the calibration plot was shown in figure 4 .

Table 2. Results of linearity

\begin{tabular}{|l|c|c|}
\hline \multirow{2}{*}{ S. No } & \multicolumn{2}{|c|}{ Amisulpride } \\
\cline { 2 - 3 } & Concentration $(\mu \mathrm{g} / \mathrm{ml})$ & Area \\
\hline \multirow{2}{*}{1} & 2.50 & 954872 \\
\hline 2 & 5.00 & 1835648 \\
\hline 3 & 7.50 & 2835698 \\
\hline 4 & 10.00 & 3789542 \\
\hline 5 & 12.50 & 4632159 \\
\hline 6 & 15.00 & 5563147 \\
\hline
\end{tabular}

Figure 4: Calibration plot of Amisulpride

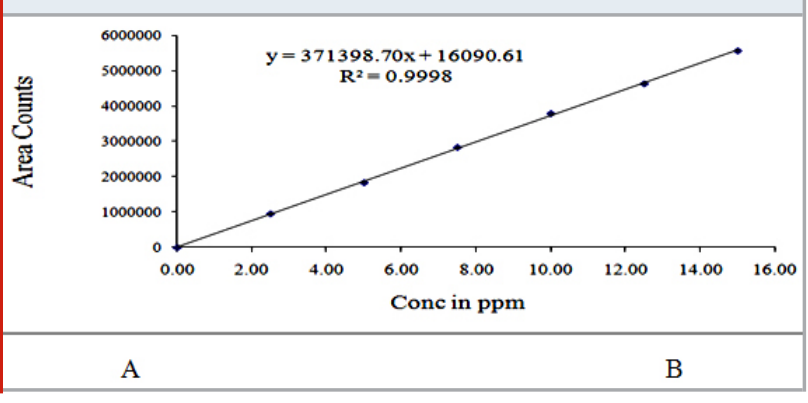

Table 3. Results of method precision

\begin{tabular}{|l|c|}
\hline S. No. & Area of Amisulpride \\
\hline 1 & 3766548 \\
\hline 2 & 3721548 \\
\hline 3 & 3742156 \\
\hline 4 & 3785451 \\
\hline 5 & 3706541 \\
\hline 6 & 3726854 \\
\hline Mean & 3741516 \\
\hline Std. dev & 29645.3731 \\
\hline \% RD & 0.79 \\
\hline
\end{tabular}

Table 4. Results of Intermediate precision

Area of Amisulpride Relative standard deviation 
Precision: Precision of this method was assessed in terms of intraday (repeatability) and (intermediate precision) variations. The intraday studies were determined by performing six repeated analysis of the sample solution of Amisulpride on the same day under the same experimental conditions (Lyo et al., 2002). The intermediate precision of the method was carried out in the same laboratory by studying the analysis with different analyst and different instrument. The method is highly precise as \%RSD values were found to be $<2 \%$. Good recoveries of the drug were obtained at each added concentration, indicating that the method was accurate. Table 3 gives the method precision results and the table 4 gives the intermediate precision results (Katch et al., 1980; Madras 2013).

Accuracy: The accuracy of the method was performed by calculating the recovery experiments at three levels (50\%, $100 \%$ and 150\%). APIs with concentration 5, 10, $15 \mu \mathrm{g} /$ $\mathrm{ml}$ of Amisulpride was prepared. The test solution was injected three times for each spike level and assay was performed as per the test method. The recovery results were close to $100 \%$ and also the RSD values were less than $\pm 2 \%$. The percentage recovery, mean and relative standard deviation were calculated. Recovery values demonstrated that the method was accurate within desired range. Accuracy results were shown in table 5.

Table 5. Results of accuracy

\begin{tabular}{|l|c|l|}
\hline Accuracy & Amount of Amisulpride & \% Recovery \\
\hline 50 & 5 & 99.1 \\
\hline 100 & 10 & 100.2 \\
\hline 150 & 15 & 99.6 \\
\hline
\end{tabular}

Robustness: Robustness of the chromatographic method was determined by varying flow rate and mobile phase composition. \% RSD was found to be within the acceptable limit. Robustness results were shown in table 6 (Leucht et al., 2013).

Table 6. Results of robustness

\begin{tabular}{|l|c|}
\hline Parameter & \% RSD of Amisulpride \\
\hline Flow $(0.8 \mathrm{ml} / \mathrm{min})$ & 0.50 \\
\hline Flow $(1.2 \mathrm{ml} / \mathrm{min})$ & 0.15 \\
\hline Organic phase $(63: 37)$ & 0.06 \\
\hline Organic phase $(77: 23)$ & 0.31 \\
\hline
\end{tabular}

Forced degradation: The proposed method can be used for release and stability studies for effective evaluations and can be considered as stability indicating method. The forced degradation study was carried out according to the ICH requirements include acid, base, oxidation, reduction, photo, thermal, hydrolysis degradation. From the chromatograms it is evident that the selected drugs were stable under the applied stress conditions though the degraded peaks were observed. Forced degradation study results were shown in table 7 .

Table 7. Results of forced degradation

\begin{tabular}{|c|c|}
\hline Stress parameter & $\begin{array}{l}\text { \% degradation } \\
\text { Amisulpride }\end{array}$ \\
\hline $\begin{array}{l}\text { Acid degradation } \\
(1 \mathrm{~N} \mathrm{HCl}+\text { reflux }+24 \mathrm{hrs})\end{array}$ & 13.6 \\
\hline $\begin{array}{l}\text { Alkali degradation } \\
(1 \mathrm{~N} \mathrm{NaOH}+\text { reflux }+24 \mathrm{hrs})\end{array}$ & 12.6 \\
\hline $\begin{array}{l}\text { Peroxide degradation } \\
(30 \% \text { Peroxide }+ \text { reflux }+24 \mathrm{hrs})\end{array}$ & 15.4 \\
\hline $\begin{array}{l}\text { Reduction degradation } \\
\text { ( } 30 \% \text { sodium bi sulphate }+24 \mathrm{hrs} \text { ) }\end{array}$ & 16.5 \\
\hline $\begin{array}{l}\text { Photo degradation (UV light (200 W h/m2) } \\
\text { and fluorescent light (1.2 million lux-hrs)) }\end{array}$ & 12 \\
\hline $\begin{array}{l}\text { Thermal degradation (Sample + heat } \\
\text { for } 6 \mathrm{hrs} \text { ) }\end{array}$ & 12.2 \\
\hline $\begin{array}{l}\text { Hydrolysis degradation } \\
\text { (1 ml HPLC water + reflux }+24 \text { hrs })\end{array}$ & 10.3 \\
\hline
\end{tabular}

The devised approach was validated in accordance with ICH requirements and found to be very precise, quick, simple, cost-effective, and sensitive to the specific pharmaceutical dosage form (Oftedal 2002; Owen 2016; Pani 2002; Perea 2009).

\section{CONCLUSION}

In this study a novel, rapid, economical, sensitive and easily available HPLC method was developed for the determination of Amisulpride in bulk and pharmaceutical dosage form. In this method shorter run time, low price, accessibility, sensitivity, reliability and reproducibility. These properties are important when a large number of samples are to be analyzed. The validation of all the parameters like linearity, accuracy, specificity, robustness, method precision were done and found to be within the acceptable limit. The RSD values for all the parameters were found to be less than $2 \%$, which indicates the validity of the method and the results obtained by this method are in fair agreement. So the proposed method could be easily applied for the routine analysis and the pharmaceutical formulations of Amisulpride in quality control laboratories without any preliminary separation.

\section{ACKNOWLEDGEMENTS}

I thankful to my guide for encouragement and supporting to finish this research work and also Shree Icon Pharmaceutical Laboratories, Vijayawada for providing laboratory facilities.

Competing Interests: There is no competing of interests 
Authors' Contributions: Autor 1 designed the study, performed the statistical analysis, wrote the protocol, and wrote the manuscript. Autor 2 to check the work and review the manuscript.

\section{REFERENCES}

Agarwal P, Sarris CE, Herschman Y, Agarwal N, Mammis A (2016). Schizophrenia and neurosurgery: A dark past with hope of a brighter future. Journal of Clinical Neuroscience;34:53-58.

Capuco A V, Akers R M (2009). The origin and evolution of lactation. Journal of Biology; 8:37.

Carmichael MA, Thomson RL, Moran LJ, Wycherley TP (2021). The impact of menstrual cycle phase on athletes' performance: a narrative review. Int J Environ Res Public Health (Review);18.

Frederick LR, Cakir 00, Arora H, Helfand BT, McVary KT. Undertreatment of erectile dysfunction: claims analysis of 6.2 million patients. The Journal of Sexual Medicine. 2014;11:2546-53.

Gerlo S, Davis JR, Mager DL, Kooijman R. Prolactin in man: a tale of two promoters. BioEssays. 2006;28:1051-5. Giardina, William J, Williams, Michael. Adrogolide $\mathrm{HCl}$ (ABT-431; DAS-431), a Prodrug of the Dopamine D1 Receptor Agonist, A-86929: Preclinical Pharmacology and Clinical Data. CNS Drug Reviews. 2006;7:305316.

Goikolea JM, Colom F, Torres I, Capapey J, Valentí M, Undurraga J, Grande I, Sanchez-Moreno J, Vieta E. Lower rate of depressive switch following antimanic treatment with second-generation antipsychotics versus haloperidol. Journal of Affective Disorders. 2013;144:191-8.

Honarmand, Azim, Safavi, Mohammadreza, Chegeni, Mansoureh, Hirmanpour, Anahita, Nazem, Masoud, Sarizdi, Seyyad Hamid. Prophylactic antiemetic effects of Midazolam, Ondansetron, and their combination after middle ear surgery. Journal of Research in Pharmacy Practice. 2016;5:16-21.

Katch VL, Campaigne B, Freedson P, Sady S, Katch FI, Behnke AR. Contribution of breast volume and weight to body fat distribution in females. Am. J. Phys. Anthropol. 1980;53:93-100.
Leucht S, Cipriani A, Spineli L, Mavridis D, Orey D, Richter F, Samara M, Barbui C, Engel RR, Geddes JR, Kissling W, Stapf MP, Lässig B, Salanti G, Davis JM Comparative efficacy and tolerability of 15 antipsychotic drugs in schizophrenia: a multiple-treatments metaanalysis. Lancet. 2013;382:951-962.

Lyo IK, Kwon JS, Lee SJ, Hann MH, Chang C, Seo, Lee SI, Renshaw PF. Decrease in Genu of the Corpus Callosum in Medication-Naïve, Early-Onset Dysthymia and Depressive Personality Disorder. Biological Psychiatry. 2002;52:1134-1143.

Madras BK. History of the discovery of the antipsychotic dopamine D2 receptor: a basis for the dopamine hypothesis of schizophrenia. Journal of the History of the Neurosciences. 2013;22:62-78.

Oftedal, Olav T. The Origin of Lactation as a Water Source for Parchment-Shelled Eggs. Journal of Mammary Gland Biology and Neoplasia. 2002;7:253-66.

Owen MJ, Sawa A, Mortensen PB. Schizophrenia. Lancet. 2016;388:86-97.

Pani L, Gessa GL. The substituted benzamides and their clinical potential on dysthymia and on the negative symptoms of schizophrenia. Molecular Psychiatry. 2002;7: 247-53.

Pani L, Gessa GL. The substituted benzamides and their clinical potential on dysthymia and on the negative symptoms of schizophrenia. Molecular Psychiatry. 2002;7:247-53.

Perea G, Navarrete M, Araque A. Tripartite synapses: astrocytes process and control synaptic information. Trends in Neurosciences. Cambridge, MA: Cell Press. 2009;32:421-431.

Suppe, Frederick. Understanding Scientific Theories: An Assessment of Developments, 1969-1998. Philosophy of Science. 1998;67:S102-S115.

Wang S, Che T, Levit A, Shoichet BK, Wacker D, Roth BL. Structure of the D2 dopamine receptor bound to the atypical antipsychotic drug risperidone. Nature. 2018;555:269-273.

Wang X, Heinz BA, Qian YW, et al. Intracellular Binding Site for a Positive Allosteric Modulator of the Dopamine D1 Receptor. Mol. Pharmacol. 2018;94:1232-1245. 